\title{
Investigation of Circulating miRNA-133, miRNA-26, and miRNA-378 as Candidate Biomarkers for Left Ventricular Hypertrophy
}

\author{
ZERRIN BARUT ${ }^{1}$, AYCA TURER CABBAR ${ }^{2}$, SEDA GULEC YILMAZ ${ }^{3}$, FATMA TUBA AKDENIZ $^{3}$, \\ MUSTAFA AYTEK SIMSEK ${ }^{2}$, BETUL CAPAR ${ }^{4}$, MUZAFFER DEGERTEKIN ${ }^{2}$, \\ ALTAY BURAK DALAN ${ }^{3}$, HALIT YEREBAKAN $^{5}$ and TURGAY ISBIR ${ }^{3}$ \\ ${ }^{I}$ Department of Basic Medical Science, Faculty of Dentistry, Antalya Bilim University, Antalya, Turkey; \\ ${ }^{2}$ Department of Cardiology, Faculty of Medicine, Yeditepe University, Istanbul, Turkey; \\ ${ }^{3}$ Department of Medical Biology, Faculty of Medicine, Yeditepe University, Istanbul, Turkey; \\ ${ }^{4}$ Department of Molecular Medicine, Institute of Health Sciences, Yeditepe University, Istanbul, Turkey; \\ ${ }^{5}$ Department of Cardiovascular Surgery, Faculty of Medicine, Yeditepe University, Istanbul, Turkey
}

\begin{abstract}
Background/Aim: Left ventricular hypertrophy $(L V H)$ involves increased muscular mass of the left ventricle due to increased cardiomyocyte size and is caused by cardiomyopathies. Several microRNAs (miRNAs) have been implicated in processes that contribute to heart disease. This study aimed to examine miRNA-133, miRNA-26 and miRNA378 as candidate biomarkers to define prognosis in patients with LVH. Patients and Methods: The study group consisted of 70 patients who were diagnosed with LVH and 16 unaffected individuals who served as the control group. Real-time polymerase chain reaction (RT-PCR) was used to analyze serum miRNA-133, miRNA-26, and miRNA-378 expression levels in LVH patients and the control group. Receiver operating characteristic (ROC) curve analysis was performed to assess the diagnostic capability of miRNA-378. Results: When crossing threshold (CT) values were compared between patient and control samples, we found that there were no statistically significant differences in miRNA-133 and miRNA-26 CT values, while the miRNA-378 expression was significantly increased in LVH patients. ROC analysis demonstrated that the expression levels of miRNA-
\end{abstract}

This article is freely accessible online.

Correspondence to: Prof. Dr. Turgay Isbir, Department of Medical Biology, Faculty of Medicine, Yeditepe University, Yerleskesi, Inonu Cad. 26 Agustos Yerleskesi, 34755 Kay1sdag1-Atasehir, Istanbul, Turkey. Tel: +90 5332823726, Fax: +90 5332823726, e-mail: turgay.isbir@yeditepe.edu.tr

Key Words: Left ventricular hypertrophy, circulating miRNA, miRNA-133, miRNA-26, miRNA-378, biomarker.
378 (AUC=0.484, $p=0.0013)$ were significantly different between groups. Conclusion: We observed a statistically significant relationship between miRNA-378 expression levels and LVH, suggesting that circulating miRNA-378 may be used as a novel biomarker to distinguish patients who have LVH from those who do not.

Left ventricular hypertrophy (LVH) is defined as increased muscular mass of the left ventricle due to increased cardiomyocyte size (1). LVH arises from either physiological processes, as seen in athletes, or pathological conditions, such as primary LVH, a result of primary myocardial diseases including hypertrophic cardiomyopathy (HCM) or dilated cardiomyopathy (DCM) (2). HCM is a genetic disease and several mutations in genes encoding sarcomeric proteins have been found to contribute to its pathology (3). Asymmetric hypertrophy has been observed while abnormal cardiomyocyte calcium cycling and hypersensitivity have been implicated as causes of impaired myofibrillar contractile function (4). DCM usually results from myocarditis or exposure to cardiotoxic agents and presents with eccentric hypertrophy (5).

Several studies have implicated miRNAs in the disease pathogenesis (6). miRNA levels relative to their target mRNAs largely determine the fate of these mRNAs, and also miRNAs are believed to participate in modulating the expression of over $60 \%$ of protein-coding genes (7). The majority of mature miRNAs either inhibit mRNA transcription or directly degrade them, while few promote mRNA transcription (8). These extracellular circulating miRNAs have been reported to be stable under a variety of extreme conditions, such as repeated freeze-thaw cycles and boiling, and are suitable for long-term storage. An increasing 
number of studies have revealed miRNAs to be potential biomarkers and emphasized their possible therapeutic roles in various diseases (9).

Several miRNAs have been implicated in the regulation of the processes involved in heart disease. Kura et al. reported miRNA-133 involvement in the regulation of ion channels, such as $\mathrm{K}^{+} / \mathrm{Na}^{+}$, contributing to arrhythmia, and its ability to regulate anti-hypertrophic genes (10). Han et al. showed miRNA expression in neurons; miRNA-26 was found to be highly expressed during atrial fibrillation (11). Several isoforms of human miRNA-378 are listed in the microRNA database. miRNA-378 variants, encoded by different genomic loci, share identical sequences, and are thus considered to have common regulatory targets. miRNA378 has potential roles in cardiac remodeling, such as enhanced expression levels when miRNA-378 is chemically modified or reduced expression levels with miRNA-378 antisense oligonucleotides (12).

This study aimed to determine the expression levels of miRNA-133, miRNA-26, and miRNA-378 in LVH and investigate their possible use as candidate biomarkers for LVH prognosis.

\section{Patients and Methods}

Study population and clinical procedures. This study included 70 patients diagnosed with $\mathrm{LVH}$, with 16 individuals without $\mathrm{LVH}$ serving as the control group. Whole blood samples of all participants were obtained from the Cardiology Department of Yeditepe University, Istanbul, Turkey. All procedures performed in this study were in accordance with the ethical standards of the 1975 Declaration of Helsinki guidelines and amendments. The research procedures were approved by the Yeditepe University Medical Faculty Ethics Committee (file no: 25.05.2017/722).

The following formula was used to evaluate patients with no major distortions of LV geometry [left ventricle end diastolic dimension (LVEDD), interventricular septal end diastole measurement (IVSd), posterior wall thickness at end-diastole (PWd)], such as hypertension:

Left ventricular mass $=$

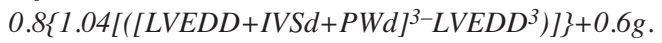

With this formula, even the smallest errors may be magnified owing to the required cubing of primary measurements. The formula (2PWTd)/(LVIDd), used to calculate relative wall thickness (RWT), permits the categorization of an increased LV mass as either concentric $(\mathrm{RWT} \geq 0.42)$ or eccentric $(\mathrm{RWT} \leq 0.42)$ hypertrophies. Furthermore, it identifies concentric remodeling of normal LV mass with an increased RWT. In this study, patient samples were selected based on those who had presented to the cardiology polyclinic with complaints of masticatory swelling of the temporalis muscle. The exact determination of the left ventricle mass served as a key factor in the successful assessment of LVH.

Blood collection. Whole blood samples were collected from 86 participants. Samples were centrifuged at $1500 \times g$ for $10 \mathrm{~min}$ and the obtained serum samples were transferred to new sterilized tubes and immediately stored at $-80^{\circ} \mathrm{C}$.

miRNA selection. In the present study, target miRNAs were selected using the "mirbase" database (13). The chosen miRNAs and their gene targets involved in LVH molecular mechanisms were assigned using the "targetscan" database (14). miRNA-26, miRNA-133, and miRNA-378 were chosen as the target miRNAs owing to their roles in LV pathogenesis.

miRNA isolation and expression analysis. miRNAs were isolated using a miRNA Serum/Plasma Isolation Kit (Qiagen, Hilden, Germany) in accordance with the manufacturer's instructions. The optical density of isolated miRNAs was measured using a NanoDrop2000 (Thermo Scientific, Waltham, MA, USA). The purity of the RNA samples was determined using the OD260/OD280 ratio and samples with ratios $>2$ were accepted as pure. miRNA isolates were converted to cDNA by reverse transcription using the miScript II RT Kit (Qiagen, Hilden, Germany). miRNA samples were quantified using the Qubit miRNA Assay Kit on a Qubit 3.0 Fluorometer (Thermo Scientific, Waltham, MA, USA). cDNA samples were stored at $-20^{\circ} \mathrm{C}$.

miRNA expression analysis by Real -Time PCR. Expression levels of miRNA-133, miRNA-26, and miRNA-378 were determined using a real-time reverse transcription-PCR (Rotor Gene-Q, Qiagen, Hilden, Germany). The miRNA-U6 housekeeping assay was used to determine the delta cycle threshold $(\Delta \mathrm{Ct})$ values of the primer (Qiagen, Hilden, Germany). SYBR Green dye (miScript SYBR Green PCR, Qiagen) was used for the determination of the target miRNA primer sequence binding (Qiagen, Hilden, Germany), cDNA sequences and mirR-U6 as a housekeeping primer (Qiagen, Hilden, Germany). Expression status of the target miRNAs was determined by calculating $\mathrm{C}_{\mathrm{T}}$ and $\Delta \mathrm{C}_{\mathrm{T}}$ normalized to the internal control (RNU6).

Statistical analyses. Statistical analyses were performed using SPSS 23.0 software (SPSS, Inc., Chicago, IL, USA). Values are expressed as mean \pm standard deviation (SD). Chi-square and Fisher's exact tests were used to compare demographic information. Differences between the patient and control groups were evaluated using Student's $t$-test. miRNA expression levels were calculated using $\mathrm{C}_{\mathrm{T}}$ and $\Delta \mathrm{C}_{\mathrm{T}}$. Altered miRNA expression levels were analyzed by Student's $t$-test and one-way analysis of variance (ANOVA). Correlations were determined using Pearson's correlation. The diagnostic value of circulating miRNA-378 was determined using receiver operating characteristic (ROC) curve analysis. MedCalc software (MedCalc Software Ltd, Ostend, Belgium) was used for ROC analysis with a $95 \%$ confidence interval (CI). A $p$-value $<0.05$ was considered statistically significant.

\section{Results}

The expression levels of circulating miRNA-133, miRNA-26, and miRNA-378 were determined in 70 patients with $\mathrm{LVH}$ and 16 controls without evidence of LVH. Table I shows the comprehensive demographic results of the participants. There were no significant differences between the two groups in terms of sex, age, body mass index (BMI), family history, 
Table I. Demographic results of patients and controls.

\begin{tabular}{|c|c|c|c|}
\hline Variable & $\begin{array}{c}\text { Controls } \\
(\mathrm{n}=16)\end{array}$ & $\begin{array}{l}\text { LVH Patients } \\
\qquad(\mathrm{n}=70)\end{array}$ & $p$-Value \\
\hline Gender & $68.8 \% / 31.2 \%$ & $71.4 \% / 28.6 \%$ & 0.831 \\
\hline Male/Female & $(\mathrm{n}=11) /(\mathrm{n}=5)$ & $(\mathrm{n}=50) /(\mathrm{n}=20)$ & \\
\hline Age (Year) & $60.63 \pm 12.45$ & $62.21 \pm 9.71$ & 0.578 \\
\hline $\begin{array}{l}\text { Smoking } \\
\text { (Active/ } \\
\text { None/Quit) }\end{array}$ & $\begin{array}{l}18.8 \% / 56.2 \% / 25 \% \\
(\mathrm{n}=3) /(\mathrm{n}=9) /(\mathrm{n}=4)\end{array}$ & $\begin{array}{l}28.6 \% / 47.1 \% / 24.3 \% \\
(\mathrm{n}=20) /(\mathrm{n}=33) /(\mathrm{n}=17)\end{array}$ & 0.707 \\
\hline $\begin{array}{l}\text { Family } \\
\text { history }\end{array}$ & $43.8 \% / 56.2 \%$ & $41.4 \% / 58.6 \%$ & 0.865 \\
\hline Yes/No & $(n=7) /(n=9)$ & $(\mathrm{n}=24) /(\mathrm{n}=34)$ & \\
\hline Total-K & $184.12 \pm 50.81$ & $192.07 \pm 40.83$ & 0.524 \\
\hline LDL & $107.43 \pm 45.12$ & $115.67 \pm 39.65$ & 0.484 \\
\hline HDL & $46.25 \pm 11.43$ & $44.58 \pm 12.20$ & 0.629 \\
\hline TG & $152.43 \pm 63.13$ & $175.64 \pm 92.86$ & 0.357 \\
\hline $\begin{array}{l}\mathrm{DM} \\
\text { Yes/No }\end{array}$ & $\begin{array}{c}25 \% / 75 \% \\
(n=4) /(n=12)\end{array}$ & $\begin{array}{l}47.1 \% / 52.9 \% \\
(\mathrm{n}=33) /(\mathrm{n}=37)\end{array}$ & 0.162 \\
\hline $\begin{array}{l}\text { HT } \\
\text { Yes/No }\end{array}$ & $\begin{array}{c}56.2 \% / 43.8 \% \\
(\mathrm{n}=9) /(\mathrm{n}=7)\end{array}$ & $\begin{array}{l}72.4 \% / 27.6 \% \\
(\mathrm{n}=42) /(\mathrm{n}=16)\end{array}$ & 0.216 \\
\hline $\begin{array}{l}\text { CAD } \\
\text { Yes/No }\end{array}$ & $\begin{array}{c}43.7 \% / 56.3 \% \\
(\mathrm{n}=7) /(\mathrm{n}=9)\end{array}$ & $\begin{array}{l}45.7 \% / 54.3 \% \\
(\mathrm{n}=32) /(\mathrm{n}=38)\end{array}$ & 0.887 \\
\hline VKI & $29.24 \pm 2.72$ & $28.77 \pm 4.40$ & 0.687 \\
\hline LVM & $88.0 \pm 13.86$ & $108.94 \pm 27.64$ & $0.005^{*}$ \\
\hline RWT & $0.401 \pm 0.021$ & $0.489 \pm 0.06$ & $<0.0001^{*}$ \\
\hline
\end{tabular}

n, Number of samples. Values are shown as provided as mean \pm standard deviation. *The difference between the groups was analyzed using the advanced chi-square test $\left(\chi^{2}\right)$ and a double independent sample Student's $t$-test.

triglyceride (TG), low-density lipoprotein (LDL), highdensity lipoprotein (HDL), hypertension (HT), diabetes mellitus (DM), and coronary artery disease (CAD). However, LV mass (LVM) and RWT were significantly different between the groups, as expected. The degree of LVH severity was assumed to be normal for $53.5 \%$ of the patients, while $19.0 \%$ had mild, $12.1 \%$ moderate and $15,5 \%$ severe LVH.

Analysis of miRNA expression. Real-time PCR was performed to measure the expression of miRNA-26, miRNA133, and miRNA-378 in human serum samples, with miRNA expression levels evaluated as $C_{T}$ and $\Delta C_{T}$ values. Analyses of the circulating miRNA expression levels between the two groups are provided in Table II.

The levels of miRNA expression were determined by comparing the $\Delta \mathrm{C}_{\mathrm{T}}$ values of the miRNAs normalized to an internal control (RNU6). When the mean $\Delta \mathrm{C}_{\mathrm{T}}$ values were compared, miRNA-378 levels were significantly different between the groups. However, there were no statistical differences in the $\Delta \mathrm{C}_{\mathrm{T}}$ values of miRNA-133 or miRNA-26 (Table III).

Comparing the $\mathrm{LVH}$ status with the miRNA $\mathrm{C}_{\mathrm{T}}$ and $\Delta \mathrm{C}_{\mathrm{T}}$ values, we found no statistically significant differences for miRNA-133 and miRNA-26 $\mathrm{C}_{\mathrm{T}}$ values between the patient
Table II. Comparison of microRNA CT and $\triangle C T$ values between left ventricular hypertrophy $(\mathrm{LVH})$ patients and controls.

\begin{tabular}{lccc}
\hline Variable & $\begin{array}{c}\text { Controls } \\
(\mathrm{n}=16)\end{array}$ & $\begin{array}{c}\text { LVH Patients } \\
(\mathrm{n}=70)\end{array}$ & $p$-Value \\
\hline miRNA-133 & & & \\
$\mathrm{C}_{\mathrm{T}}($ mean $\pm \mathrm{SD})$ & $32.57 \pm 5.65$ & $31.62 \pm 5.05$ & 0.684 \\
$\Delta \mathrm{C}_{\mathrm{T}}($ mean $\pm \mathrm{SD})$ & $5.51 \pm 5.87$ & $1.89 \pm 11.59$ & 0.398 \\
miRNA-26 & & & \\
$\mathrm{C}_{\mathrm{T}}($ mean $\pm \mathrm{SD})$ & $23.12 \pm 3.10$ & $26.59 \pm 2.29$ & 0.522 \\
$\Delta \mathrm{C}_{\mathrm{T}}($ mean $\pm \mathrm{SD})$ & $-4.34 \pm 3.37$ & $-5.20 \pm 3.54$ & 0.438 \\
miRNA-378 & & & \\
$\mathrm{C}_{\mathrm{T}}($ mean $\pm \mathrm{SD})$ & $21.91 \pm 2.36$ & $24.69 \pm 4.81$ & $0.029^{*}$ \\
$\Delta \mathrm{C}_{\mathrm{T}}(\operatorname{mean} \pm \mathrm{SD})$ & $-5.55 \pm 2.65$ & $0.79 \pm 7.86$ & $0.020^{*}$ \\
\hline
\end{tabular}

$\mathrm{n}$, Number of samples; $\mathrm{C}_{\mathrm{T}}$, cycle threshold; $\Delta \mathrm{C}_{\mathrm{T}}$, delta cycle threshold. $\mathrm{C}_{\mathrm{T}}$ and $\Delta \mathrm{C}_{\mathrm{T}}$ values are shown as mean \pm standard deviation. ${ }^{*} \mathrm{The}$ difference between the groups was analyzed using the advanced chisquare test $\left(\chi^{2}\right)$ and a double independent sample Student's $t$-test.

and control groups; however, miRNA-378 levels were downregulated in the patient group. Statistically significant differences were found between the patient and control groups for miRNA-378 $\mathrm{C}_{\mathrm{T}}(p=0.029)$ and $\Delta \mathrm{C}_{\mathrm{T}}(p=0.020)$ values.

The $\mathrm{C}_{\mathrm{T}}$ and $\Delta \mathrm{C}_{\mathrm{T}}$ values of miRNA-378 were evaluated based on the LVH status of the patients. Comparison of mean $\mathrm{C}_{\mathrm{T}}$ and $\Delta \mathrm{C}_{\mathrm{T}}$ values revealed a significant relationship between miRNA-378 expression and LVH status $(p=0.029$ and $p=0.020)$. We also compared LVH types with miRNA$378 \mathrm{C}_{\mathrm{T}}$ and $\Delta \mathrm{C}_{\mathrm{T}}$ values. The eccentric group showed the highest $\mathrm{C}_{\mathrm{T}}$ expression level, followed by the remodeling group, hypertrophy group and control group ( $p=0.001)$. In contrast, the remodeling group had the highest $\Delta \mathrm{C}_{\mathrm{T}}$ expression level, followed by the eccentric LVH patients, hypertrophy group, and control group $(p=0.003)$.

miRNA ROC analysis. ROC curve analysis was performed to investigate the usefulness of miRNA-378 as a diagnostic biomarker for $\mathrm{LVH}$, using both $\mathrm{C}_{\mathrm{T}}$ and $\Delta \mathrm{C}_{\mathrm{T}}$ values. Using $\mathrm{C}_{\mathrm{T}}$ values, miRNA-378 showed a specificity of $100 \%$ and a sensitivity of $25.5 \%$ (95\% CI $=0.482-0.732, \mathrm{AUC}=0.612$, $p=0.0013$ ) (Figure 1a). In addition, the levels of miRNA-378 expression were determined by comparing the $\Delta \mathrm{C}_{\mathrm{T}}$ values of miRNA and the internal control (RNU6). The miRNA-378 $\Delta \mathrm{C}_{\mathrm{T}}$ values had a specificity of $69.2 \%$ and a sensitivity of $76.5 \% \quad(95 \% \quad \mathrm{CI}=0.602-0.831, \quad \mathrm{AUC}=0.484, p=0.0017)$ (Figure 1b). The results of the ROC curve analyses suggest that serum miRNA-378 levels could be a candidate biomarker for the diagnosis of LVH.

However, there was no significant relationship between miRNA-133 and miRNA-26 expression and LVH $(p=0.110$ and $p=0.782$ ), and ROC analysis performed to demonstrate the biomarker effect of these miRNAs confirmed these findings (Figure 2). 


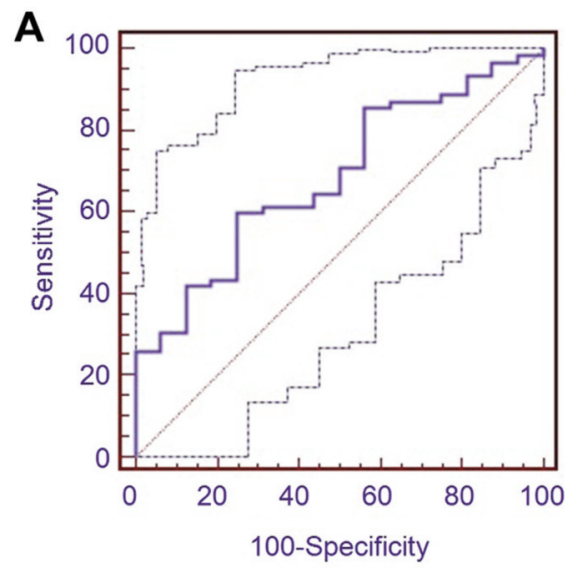

$\mathrm{AUC}=0.612$

$95 \% \mathrm{Cl}=0.482-0.732$ $p=0.0013$

Sensitivity: 25.5

Specificity: 100.0

Criterion: $>27.04$

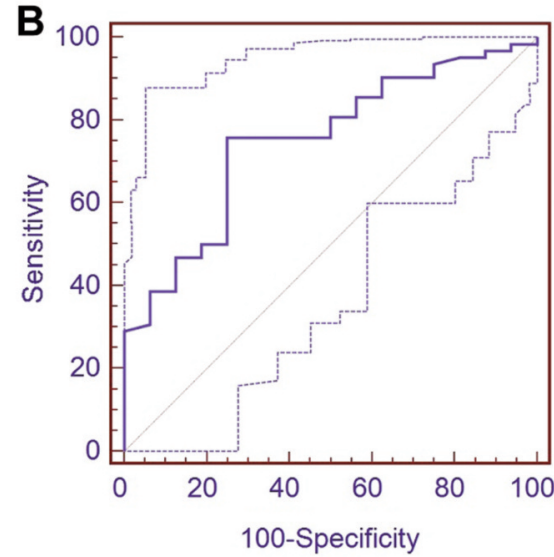

$A \cup C=0.484$

$95 \% \mathrm{Cl}=0.602-0.831$

$p=0.0017^{*}$

Sensitivity: 76.5

Specificity: 69.2

Criterion: $>5.38$

Figure 1. ROC analysis of miRNA-378 expression in patients with LVH. (a) miRNA-378 Cm values. (b) miRNA-378 $\triangle$ Cm values. $100-S p e c i f i c i t y$ refers to the false positive rate.
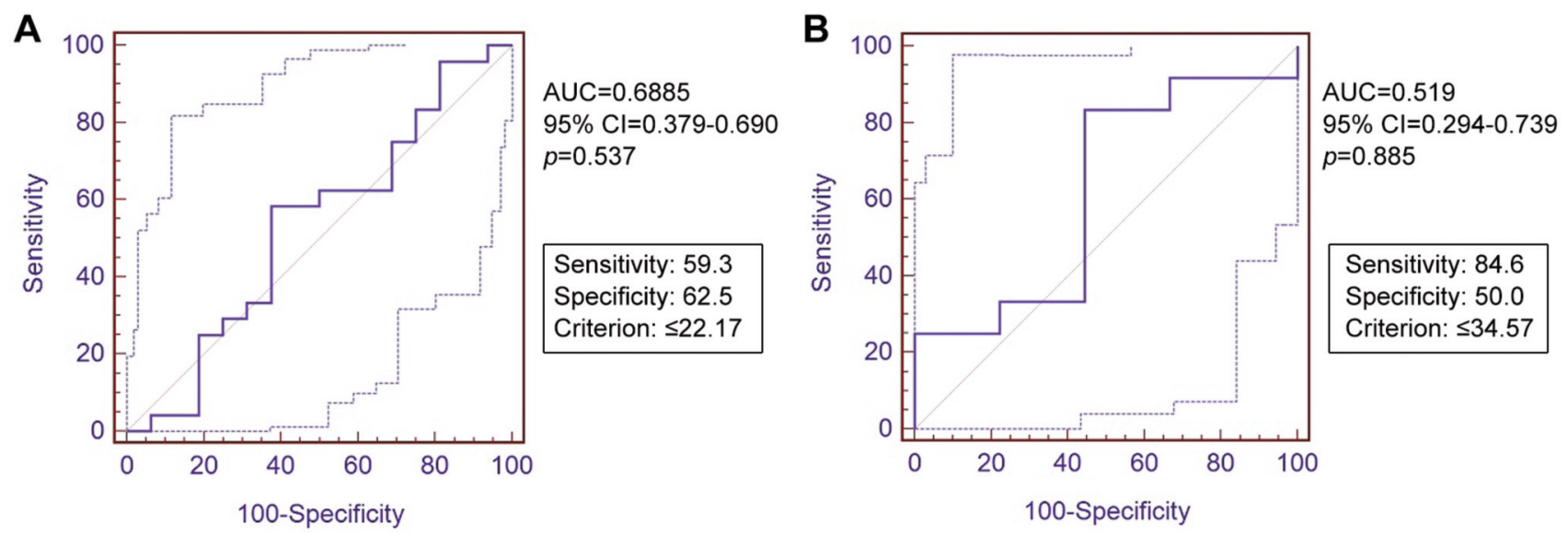

Figure 2. ROC analysis of miRNA Cm values of patients with LVH. (a) miRNA-26 Cm values. (b) miRNA-133 Cm values. 100-Specificity refers to the false positive rate.

Table III. Comparison of miRNA CT and $\triangle C T$ values between different patient groups.

\begin{tabular}{|c|c|c|c|c|c|}
\hline Variable & $\begin{array}{l}\text { Control } \\
(\mathrm{n}=16)\end{array}$ & $\begin{array}{l}\text { Hypertrophy } \\
(\mathrm{n}=34)\end{array}$ & $\begin{array}{c}\text { Remodeling } \\
(\mathrm{n}=34)\end{array}$ & $\begin{array}{l}\text { Eccentric } \\
\quad(\mathrm{n}=2)\end{array}$ & $p$-Value \\
\hline \multicolumn{6}{|c|}{ miRNA-133 } \\
\hline $\mathrm{C}_{\mathrm{T}}$ & $32.57 \pm 5.65$ & $30.76 \pm 4.20$ & 0 & $41.83 \pm 0$ & 0.110 \\
\hline$\Delta \mathrm{C}_{\mathrm{T}}$ & $5.51 \pm 5.87$ & $3.49 \pm 7.41$ & 0 & $-7.66 \pm 30.48$ & 0.232 \\
\hline \multicolumn{6}{|c|}{ miRNA-26 } \\
\hline $\mathrm{C}_{\mathrm{T}}$ & $23.12 \pm 3.10$ & $22.63 \pm 2.26$ & 0 & $22.06 \pm 3.68$ & 0.782 \\
\hline$\Delta \mathrm{C}_{\mathrm{T}}$ & $-4.34 \pm 3.37$ & $-5.10 \pm 3.62$ & 0 & $-6.51 \pm 2.77$ & 0.641 \\
\hline \multicolumn{6}{|c|}{ miRNA-378 } \\
\hline $\mathrm{C}_{\mathrm{T}}$ & $21.91 \pm 2.36$ & $22.66 \pm 3.71$ & $26.44 \pm 4.93$ & $27.12 \pm 8.36$ & $0.001 *$ \\
\hline$\Delta \mathrm{C}_{\mathrm{T}}$ & $-5.55 \pm-2.65$ & $-3.52 \pm 8.21$ & $1.79 \pm 6.84$ & $-1.45 \pm 7.45$ & $0.003^{*}$ \\
\hline
\end{tabular}

n, Number of samples; $\mathrm{SD}$, standard deviation; $\mathrm{C}_{\mathrm{T}}$, cycle threshold; $\Delta \mathrm{C}_{\mathrm{T}}$, delta cycle threshold. $\mathrm{C}_{\mathrm{T}}$ and $\Delta \mathrm{C}_{\mathrm{T}}$ values are shown as mean \pm standard deviation. ${ }^{*} p<0.05$. The difference between the groups was analyzed using one-way ANOVA. 


\section{Discussion}

LVH is an important contributor to cardiovascular morbidity and mortality. Several factors contribute to the development of ventricular hypertrophy, including hypertension, CAD, valvular pathologies, obesity, or a combination of these (1). Many studies have described a relationship between cardiovascular diseases and miRNAs. The latter are important for the differentiation of cardiac cells, angiogenesis, and myocyte development. Additionally, miRNA level variations may lead to various cellular abnormalities, such as endothelial dysfunction and proliferation, as well as differentiation of vascular smooth muscle cells (VSMCs), leading to cardiovascular disease (15).

miRNAs are single stranded non coding RNAs that regulate gene expression by degrading or repressing target mRNAs (16). Owing to their stability in response to alterations in $\mathrm{pH}$ and temperature, they can be used as noninvasive biomarkers that circulate in body fluids and solid tissues (17). Indeed, circulating miRNAs have been investigated as potential biomarkers for diagnostic and therapeutic purposes. Thus far, a limited number of studies have investigated the role of miRNAs and target genes associated with atherosclerosis as potential biomarkers for molecular diagnosis (18).

Matkovich et al. observed striking differences between the in vitro and in vivo phenotypes of miRNA-133a expression and suggested that mRNA signatures cannot reliably predict either direct miRNA targets or major miRNA effects (19). Our results align with their conclusion, and we could not identify miRNA-133 as a biomarker in LVH.

miR-26a is known to modulate endothelial cell-associated angiogenesis (20), cardiac hypertrophy (21), and VSMC differentiation (22) making it a major player in the preservation of cardiovascular health. However, we did not identify a relationship between LVH and the mir-26 family in this study, which could be due to the limited number of Turkish patients in our participant groups. Whether the miRNA-26 family does indeed play a role in LVH requires further investigation.

The current study showed that the mean $\mathrm{C}_{\mathrm{T}}$ and $\Delta \mathrm{C}_{\mathrm{T}}$ values indicating miRNA-378 expression levels were significantly different between the patient and control groups ( $p=0.001$ and 0.003 , respectively). Our findings correlate with those of Yuan et al., who demonstrated that miRNA-378 is highly expressed during cardiac remodeling. Based on this information, they proposed that this miRNA regulates cardiac fibrosis (12). Their study showed that miRNA-378 has antihypertrophic activity and plays a crucial role in mediating anti-fibrotic effects in heart muscle cells, suggesting that this miRNA plays a dual role in suppressing cardiac hypertrophy and cardiac fibrosis. More importantly, it also serves as a mediator of intercellular communication and can be released by cardiomyocytes under pressure overload, entering cardiac fibroblasts in a secretory manner (12). Ganesan et al. showed that miRNA-378 knockout mice experiencing a stress response showed severe cardiac fibrosis when compared with wild-type mice. They also demonstrated that miRNA-378 regulates cardiomyocyte hypertrophy by suppressing genes controlling MAP kinase pathways (23). The angiogenic effects of miRNA-378 determined by Zhang et al. showed that miRNA-378 has a positive effect on osteogenesis and angiogenesis by stimulating vascular endothelial growth factor. They reported that overexpression of miRNA-378 enhanced angiogenic capacity (24).

Another study evaluated the prediction capacity of miRNA-378 in CAD. Li et al. applied ROC curve analysis to miRNA-378 levels in CAD patients and showed that altered miRNA-378 expression could be a predictive noninvasive biomarker for coronary artery lesions (25). Our result is consistent with this report, which highlight the importance of miRNA-378 expression in these conditions, although mechanistic studies are needed to confirm its potential as a biomarker. Overall, our results align with those of several previous studies that indicate miRNA-378 to be a key factor involved in a number of cellular and organic metabolic processes. Thus, high expression of miRNA-378 could be a candidate biomarker for the diagnosis of LVH.

\section{References}

1 Lorell $\mathrm{BH}$ and Carabello BA: Left ventricular hypertrophy: pathogenesis, detection, and prognosis. Circulation 102(4): 470479, 2000. PMID: 10908222. DOI: 10.1161/01.cir.102.4.470

2 Lazzeroni D, Rimoldi O and Camici PG: From left ventricular hypertrophy to dysfunction and failure. Circ J 80: 555-564, 2016. PMID: 26853555. DOI: 10.1253/circj.CJ-16-0062

3 Wigle ED, Rakowski H, Kimball BP and Williams WG: Hypertrophic cardiomyopathy. Clinical spectrum and treatment. Circulation 92(7): 1680-1692, 1995. PMID: 7671349. DOI: 10.1161/01.cir.92.7.1680

4 Thierfelder L, Watkins H, MacRae C, Lamas R, McKenna W, Vosberg HP, Seidman JG and Seidman CE: Alpha-tropomyosin and cardiac troponin $\mathrm{T}$ mutations cause familial hypertrophic cardiomyopathy: a disease of the sarcomere. Cell 77(5): 701-712, 1994. PMID: 8205619. DOI: 10.1016/0092-8674(94)90054-x

5 Khouri MG, Peshock RM, Ayers CR, de Lemos JA and Drazner MH: A 4-tiered classification of left ventricular hypertrophy based on left ventricular geometry: the Dallas heart study. Circ Cardiovasc Imaging 3(2): 164-171, 2010. PMID: 20061518. DOI: $10.1161 /$ CIRCIMAGING.109.883652

6 Li H, Gao F, Wang X, Wu J, Lu K, Liu M, Li R, Ding L and Wang $\mathrm{R}$ : Circulating microRNA-378 levels serve as a novel biomarker for assessing the severity of coronary stenosis in patients with coronary artery disease. Biosci Rep 39(5): BSR20182016, 2019. PMID: 31064817. DOI: 10.1042/BSR20182016

7 Kim VN, Han J and Siomi MC: Biogenesis of small RNAs in animals. Nat Rev Mol Cell Biol 10(2): 126-139, 2009. PMID: 19165215. DOI: $10.1038 / \mathrm{nrm} 2632$ 
8 Jones-Rhoades MW, Bartel DP and Bartel B: MicroRNAs and their regulatory roles in plants. Annu Rev Plant Biol 57: 19-53, 2006. PMID: 16669754. DOI: 10.1146/annurev.arplant.57.032905. 105218

9 Weiler J, Hunziker J and Hall J: Anti-miRNA oligonucleotides (AMOs): ammunition to target miRNAs implicated in human disease? Gene Ther 13(6): 496-502, 2006. PMID: 16195701. DOI: $10.1038 /$ sj.gt.3302654

10 Kura B, Parikh M, Slezak J and Pierce GN: The influence of diet on MicroRNAs that impact cardiovascular disease. Molecules 24(8): 1509, 2019. PMID: 30999630. DOI: 10.3390/ molecules 24081509

11 Han J, Denli AM and Gage FH: The enemy within: intronic miR-26b represses its host gene, ctdsp2, to regulate neurogenesis. Genes Dev 26(1): 6-10, 2012. PMID: 22215805. DOI: $10.1101 / \mathrm{gad} .184416 .111$

12 Yuan J, Liu H, Gao W, Zhang L, Ye Y, Yuan L, Ding Z, Wu J, Kang L, Zhang X, Wang X, Zhang G, Gong H, Sun A, Yang X, Chen R, Cui Z, Ge J and Zou Y: MicroRNA-378 suppresses myocardial fibrosis through a paracrine mechanism at the early stage of cardiac hypertrophy following mechanical stress. Theranostics 8(9): 2565-2582, 2018. PMID: 29721099. DOI: $10.7150 /$ thno. 22878

13 Mirbase Database, 2020. Available at: http://www.mirbase.org/ cgi-bin/mirna [Last accessed on $1^{\text {st }}$ July 2020]

14 TargetScan - Prediction of microRNA targets, 2020. Available at: http://www.targetscan.org [Last accessed on $1^{\text {st }}$ June 2020]

15 Min PK and Chan SY: The biology of circulating microRNAs in cardiovascular disease. Eur J Clin Invest 45(8): 860-874, 2015. PMID: 26046787. DOI: 10.1111/eci.12475

16 Bartel DP: MicroRNAs: target recognition and regulatory functions. Cell 136(2): 215-233, 2009. PMID: 19167326. DOI: 10.1016/j.cell.2009.01.002

17 Weber J, Baxter D, Zhang S, Huang D, How huang K, Jen lee M, Galas D and Wang K: The microRNA spectrum in 12 body fluids. Clinical Chemistry 56(11): 1733-1741, 2020. DOI: 10.1373/clinchem.2010.147405

18 Churov A, Summerhill V, Grechko A, Orekhova V and Orekhov A: MicroRNAs as Potential Biomarkers in Atherosclerosis. Int J Mol Sci 20(22): 5547, 2019. PMID: 31703274. DOI: 10.3390/ ijms 20225547
19 Matkovich SJ, Wang W, Tu Y, Eschenbacher WH, Dorn LE, Condorelli G, Diwan A, Nerbonne JM and Dorn GW 2nd: MicroRNA-133a protects against myocardial fibrosis and modulates electrical repolarization without affecting hypertrophy in pressure-overloaded adult hearts. Circ Res 106(1): 166-175, 2010. PMID: 19893015. DOI: 10.1161/CIRCRESAHA. 109.202176

20 Icli B, Wara A, Moslehi J, Sun X, Plovie E, Cahill M, Marchini J, Schissler A, Padera R, Shi J, Cheng H, Raghuram S, Arany Z, Liao R, Croce K, Macrae C and Feinberg M: MicroRNA-26a regulates pathological and physiological angiogenesis by targeting BMP/SMAD1 signaling. Circulation Research 113(11): 1231-1241, 2018. DOI: 10.1161/CIRCRESAHA.113.301780

21 Wei C, Kim IK, Kumar S, Jayasinghe S, Hong N, Castoldi G, Catalucci D, Jones WK and Gupta S: NF- $x$ B mediated miR-26a regulation in cardiac fibrosis. J Cell Physiol 228(7): 1433-1442, 2013. PMID: 23254997. DOI: $10.1002 /$ jcp. 24296

22 Leeper NJ and Cooke JP: MicroRNA and mechanisms of impaired angiogenesis in diabetes mellitus. Circulation 123(3): 236-238, 2011. PMID: 21220736. DOI: 10.1161/ CIRCULATIONAHA.110.003855

23 Ganesan J, Ramanujam D, Sassi Y, Ahles A, Jentzsch C, Werfel S, Leierseder S, Loyer X, Giacca M, Zentilin L, Thum T, Laggerbauer B and Engelhardt S: MiR-378 controls cardiac hypertrophy by combined repression of mitogen-activated Protein Kinase pathway factors. Circulation 127(21): 2097-2106, 2018. DOI: 10.1161/CIRCULATIONAHA.112.000882

24 Zhang B, Li Y, Yu Y, Zhao J, Ou Y, Chao Y, Yang B and Yu X: MicroRNA-378 promotes osteogenesis-angiogenesis coupling in BMMSCs for potential bone regeneration. Anal Cell Pathol (Amst) 2018: 8402390, 2018. PMID: 29686962. DOI: $10.1155 / 2018 / 8402390$

$25 \mathrm{Li} \mathrm{Y}$ and Kowdley KV: MicroRNAs in common human diseases. Genomics Proteomics Bioinformatics 10(5): 246-253, 2012. PMID: 23200134.DOI: 10.1016/j.gpb.2012.07.005

Received February 1, 2021

Revised February 4, 2021

Accepted February 11, 2021 